\title{
OBSERVATIONS ON CHYTRIDIACEOUS PARASITES OF PHANEROGAMS. \\ II. A PRELIMINARY STUDY OF THE OCCURRENCE OF EPHEMERAL SPORANGIA IN THE PHYSODERMA DISEASE OF MAIZE ${ }^{1}$
}

\section{F. K. Sparrow ${ }^{2}$}

The Physoderma disease of maize and teosinte is well known in the more southerly regions of the United States, where in certain years it may be very destructive. Although first described from India by Shaw (1912), it was almost simultaneously discovered in this country by several observers. Whether or not it is of American origin or has spread to these native American plants from some oriental member of the Maydeae and subsequently transported to this hemisphere is an interesting question, about which at the moment there is little information.

A rather full account of the occurrence, distribution and causal organism, a chytrid, has been given by Tisdale (1919). Further information on spore germination, varietal differences of the host plant to infection, etc., may be found in papers by Eddins (1933) and Voorhees (1933).

As pointed out in a previous paper (Sparrow, 1946) species of Physoderma have two well-marked and distinctive phases in their life cycle. One, the strongly polycentric endobiotic thallus, extends through many cells and by reason of the masses of dark-colored resting spores formed on it is visible macroscopically as aggregations of pustules, warts, streaks, etc. The other, so far as now known without connection with the endobiotic phase is monocentric and consists of a thin-walled, epibiotic, socalled "ephemeral sporangium" and an endobiotic rhizoidal system of limited extent confined to a single host cell. This phase is completely invisible save microscopically, and has no apparent effect upon the area of host tissue around it.

On corn, the external manifestations of the endobiotic thalli have been well described and portrayed by 'Tisdale and Eddins and need not be repeated here. Whereas this phase is well known, the epibiotic, ephemeral sporangium remained unreported until 1934 when a brief note on its occurrence in this species was published (Sparrow, 1934).

$\mathrm{The}^{3}$ resting spores of the endobiotic thallus, enormous numbers of which are formed in infected areas, are ovoid to nearly spherical and strongly flattened on one surface (fig. 1, 2). The contour is strikingly regular, the double wall $3 \mu$ thick, amber colored and, save for the occasional occurrence of a short spine, completely smooth. Contrary to the

1 Received for publication October 11, 1946

2 Contribution from the Department of Botany, University of Michigan, No. 841. Acknowledgment is made to the Faculty Research Fund, University of Michigan, for financial aid which facilitated publication of this paper.

${ }^{3}$ I am indebted to Professor J. N. Couch of the University of North Carolina for Physoderma-infected material of maizs. statement by Jones and Drechsler (1920), no pits could be found after treatment with clearing agents. There was no tendency for the spores to aggregate in groups together with residual host material. They varied in size from $20-30 \mu$ in longest diameter by $18-24 \mu$, the precise range given by Tisdale.

Germination of THE resting spores.-The resting spores will germinate readily in distilled water at $23-30^{\circ} \mathrm{C}$. in diffuse daylight after $24-48$ hours, the precise time differing with different spores. During this process, changes in the contents of the spore occur which are not essentially different from those previously described for Physoderma Menyanthis (Sparrow, 1946). One distinction, however, was noted in comparing germination of the two species, namely, that in $P$. zeae-maydis a well-defined operculum was always dehisced. This structure was only occasionally observed in the Menyanthes parasite. At about the time the globule of the resting spore of $P$. zeae-maydis was nearly completely fragmented, the flattened face of the spore split circumscissilly as the finger-like sporangium was slowly extruded. The sporangium was thin-walled, with a broad base and relatively short, seldom exceeding $13 \mu$ in length. As it protruded from the body of the resting spore, the dehisced operculum, $13-19 \mu$ in diameter, was either pushed aside, or carried up with the elongating sporangium (fig. 3-5). Organization of the contents of the sporangium into zoospores and their discharge through an apical pore formed after the deliquescence of a papilla were essentially like those already described for $P$. Menyanthis.

The zoospores from germinated resting spores are somewhat ellipsoidal, approximately $7 \times 5 \mu$ while in motion, and bear a highly refractive, eccentric, colorless globule which frequently is seen to protrude from the body of the spore while it is in motion (fig. 6). There is a single posterior flagellum 20-25 $\mu$ long. Occasionally in living spores and always in appropriately stained ones there is visible a well-defined nuclear cap (fig. 12b), of a type commonly formed throughout all the posteriorly uniflagellate Phycomycetes. The zoospores are capable of both swimming and amoeboid types of movement. No instances of conjugation of these zoospores such as reported by Ojerholm (193.) were observed.

Formatron of ephemeral sporangia.-After a period of motility of variable duration, usually not over 12 hours in any given group of germinating resting spores, the swarmers become quiescent. In distilled water alone, as they come to rest, they undergo for a few minutes amoeboid movement, 
after which they become motionless, absorb their flagellum and round off, soon thereafter falling prey to bacteria and microscopic animals.

To follow the development of zoospores from germinated resting spores on living host material the following procedure was employed. Each of ten
Ward cells had inserted into one of its open arms a corn seedling (Golden Bantam) oriented so that its coleoptile and first true leaves protruded into the cell. The opposite end of the seedling was swathed in wet absorbent cotton. A cover glass bearing a suspension of swarming zoospores in a hanging
!

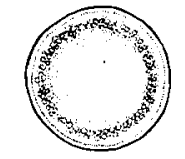

2
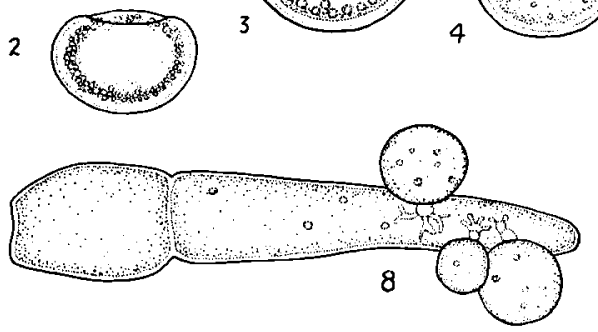

9

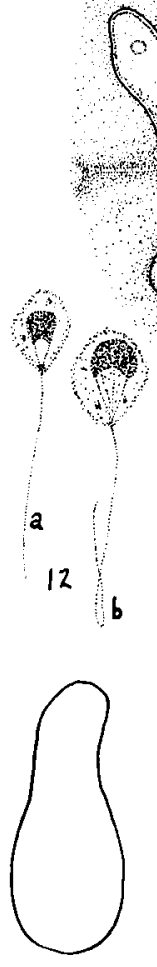

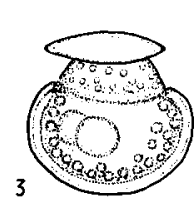

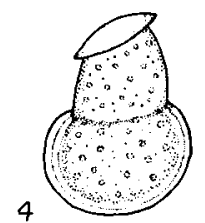

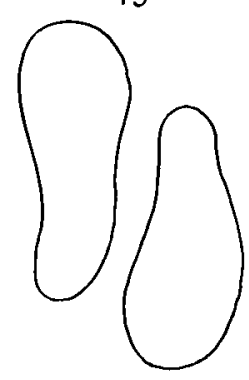

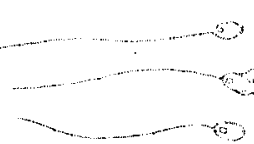

13

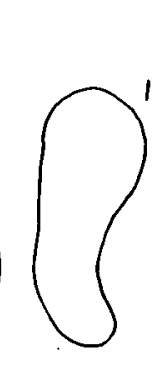

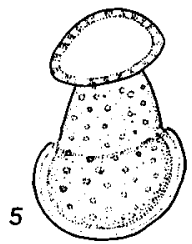
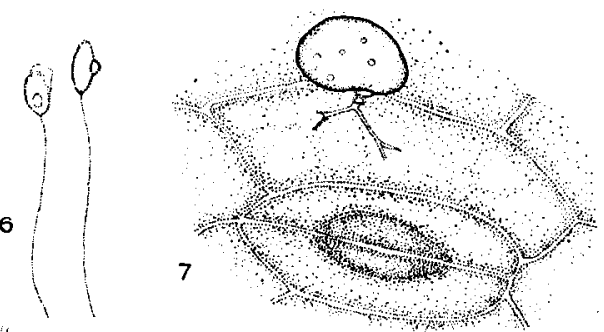

10
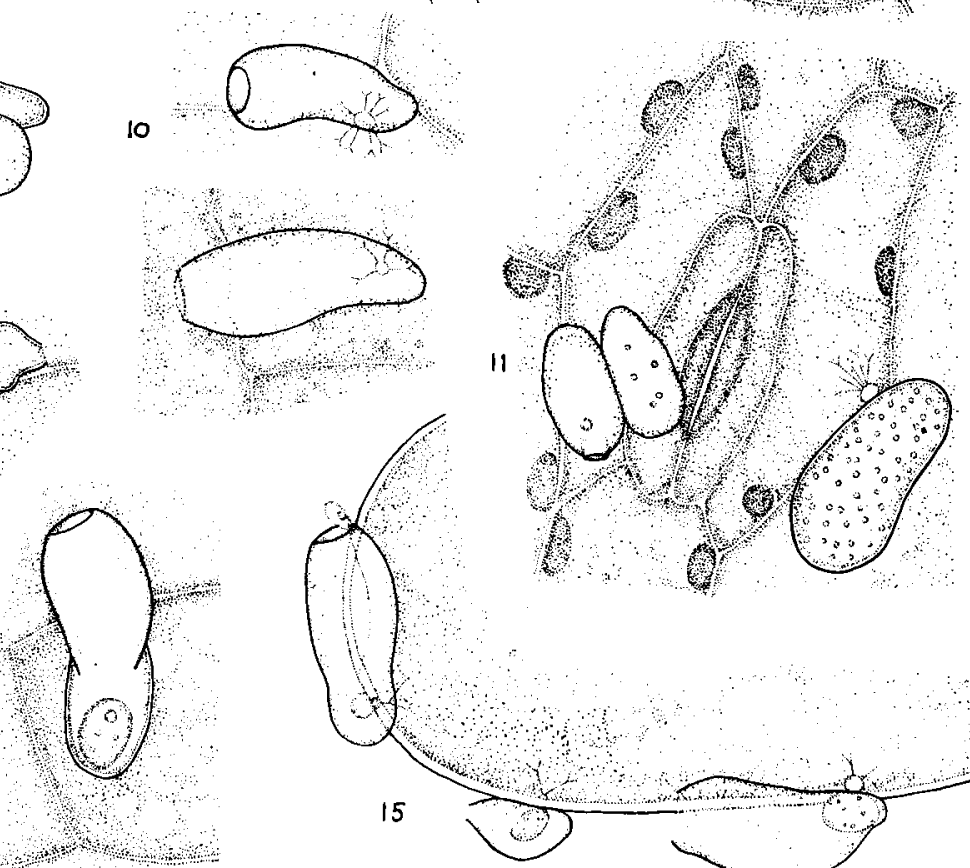

14
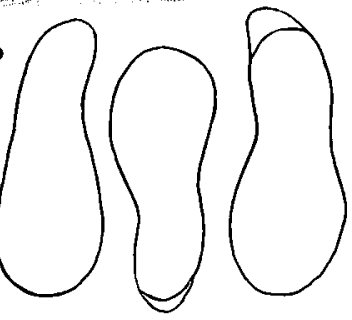

15
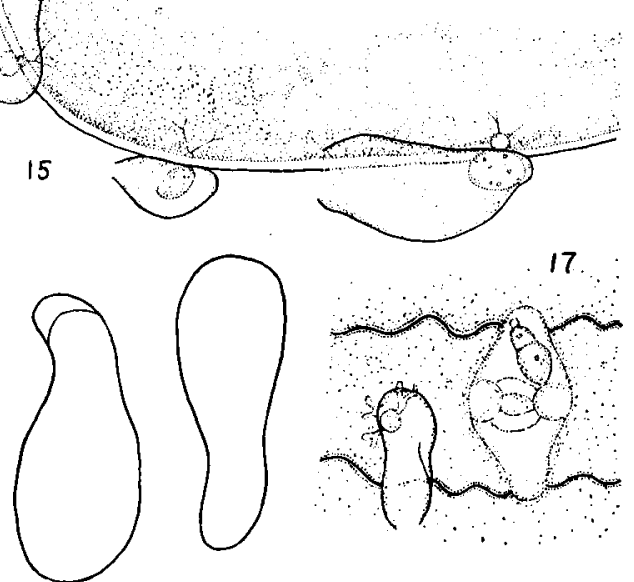

17

Fig. 1-17. Physoderma zecte-maydis. All figures except fig. 12, $\times 750$; fig. 12, $\times 1650 .-$ Fig. 1. Resting spore, top view.-Fig. 2. Same, side view.-Fig. 3-5. Stages in formation of sporangium by germinating resting spore. Note the dehisced operculum being carried up by the enlarging sporangium.-Fig. 6. Two zoospores from a germinated resting spore.-Fig. 7, 8. Young, developing ephemeral sporangia.-Fig. 9. Group of same, some showing the unenlarged portion of zoospore cyst.-Fig. 10. Two empty ephemeral sporangia.-Fig. 11. Group of sporangia.-Fig. 12. (a) Fixed and killed zoospore from ephemeral sporangium stained with gentian violet to show internal structure. (b) Zcospore from germinated resting spore treated similarly. Note differences in size, particularly of dark-staining nuclear cap.-Fig. 13. Three living zoospores formed by ephemeral sporangia.-Fig. 14. Empty ephemeral sporangium with new sporangium forming.-Fig. 15. Three ephemeral sporangia with new sporangia forming by internal proliferation.-Fig. 16. Outline drawings of a group of ephemeral sporangia to show similarity in shape. Three show internal proliferation.-Fig. 17. Stomatal apparatus bearing a two celled turbinate organ. Empty ephemeral sporangium nearby. 
drop of water was placed over the cell in the usual manner. The corn seedling was then tilted so that its tip rested in the hanging drop. By this means the seedling was relatively undisturbed and a certain amount of direct observation was possible. A suitable series of controls containing hanging drops of sterile water alone was also prepared and placed with the others.

At a room temperature of approximately $23^{\circ} \mathrm{C}$. (lower at night) and in diffuse daylight many of the zooospores had come to rest on the host tissue and encysted after 12-30 hours. During the ensuing 2. hours, these spores penetrated the host and their bodies slowly enlarged and elongated (fig. 7-9). As in other species of the genus, a portion of the zoospore cyst failed to expand and remained visible on some sporangia (fig. 9). Three days after the motile spores had come to rest on the host, mature ephemeral sporangia had developed. These were elongate, asymmetrical and somewhat slippershaped, usually $13-36 \mu$ long by $10-15 \mu$ in widest diameter with their long axis parallel with the surface of the host (fig. 9-11, 16). Near the narrower end of the sporangium the rhizoidal system is attached. So far as could be observed, this consisted of a small spherical apophysis from which radiated a somewhat rudimentary, once-branched system of rhizoids. This vegetative system was confined to a single cell in striking contrast to that which bore the resting spores. At the opposite tip of the sporangium there was formed at maturity a broad, blunt papilla which deliquesced to form a relatively wide pore through which many zoospores escaped (fig. 15). These swarmers were ellipsoidal, $5 \times 3 \mu$ and bore a small eccentric refractive, colorless globule and a posterior flagellum $15-20 \mu$ long. They were capable of rapid swimming or prolonged amoeboid movement (fig. 13). Their internal structure was entirely like that found in the large zoospores from germinated resting spores (fig. 12. left). The difference in the size of these two swarmers is shown by comparing fig. 6 and 13 , and fig. $12 a$ and $b$.

On the floor of discharged sporangia at the point of attachment of the rhizoidal system there was often present a small knob of presumably nucleated protoplasm which steadily enlarged to form another, somewhat smaller sporangium after $2 \cdot \mathbf{1 - 3 6}$ hours (fig. 14, 15). Such internal renewal of growth or "proliferation" has been noted in other species of the genus where ephemeral sporangia have been discovered (Büsgen, 1887; Clinton, 1902; Sparrow, 1946).

There is no conclusive evidence as yet to show that zoospores from ephemeral sporangia form new ephemeral sporangia such as was demonstrated to be true in Physoderma Menyanthis. It is likely that they can. Neither has it been shown that the zoospores function as gametes, as suggested earlier (Sparrow, 1940). Further work is in progress on these important aspects of the life history of the parasite.
In the present material, no evidence of the strikingly polycentric endobiotic rhizoidal system and its characteristic turbinate organs was observed in cultures less than a week old. It must be admitted that the opacity of the host tissue could easily have made it invisible. The first trace of this thallus was found in the stomatal apparatus of a young leaf. where, in the vicinity of an empty ephemeral sporangium, a typical two-celled turbinate cell had been formed (fig. 17). A further study of the development and maturing of this polycentric rhizoidal system is in progress.

Discussion.- In spite of the considerable pathological work already accomplished, the causal agent of the Physoderma disease of maize is in need of further investigation, particularly from the standpoint of the precise rôle of the ephemeral sporangia in the dissemination and life history of the fungus. Since both the presence of ephemeral sporangia and their effect on the host tissue are invisible to the unaided eye, this phase will necessarily have to be studied under special conditions. It would also be of interest to know if all diseased parts of the plant have resulted from infections initiated by zoospores from germinated resting spores, or if only the lowermost first leaves were so infected, the remainder being due to zoospores from ephemeral sporangia. If future observations substantiate the present writer's hypothesis, i.e., that these smaller zoospores are gametes and that the endobiotic system is diploid, then each endobiotic, polycentric rhizoidal system bearing many dark-colored resting spores arises solely from a biflagellate zygote. This conjecture is not vitiated by the discovery in $P$. Menyanthis that the zoospores from ephemeral sporangia apparently form only new ephemeral sporangia, for it is possible that in the absence of compatible gametes with which to fuse, they may function as zoospores.

\section{SUMMARY}

Physoderma zeae-maydis, the cause of the "Physoderma disease" of maize and teosinte, has been found to possess, in addition to the well known endobiotic resting spore stage visible to the eye, an epibiotic phase invisible save microscopically. Each of the numerous zoospores formed at the germination of the resting spore is potentially capable of forming one of these thalli. The epibiotic phase consists of a thin-walled slipper-shaped sporangium which rests on the outer surface of the host and bears inside the host cell a small apophysis and short, bushy rhizoidal system. There is no organic connection between the two phases. These "ephemeral" sporangia produce numerous zoospores which are slightly smaller than those formed at the germination of the resting spores. From analogy with Physoderma Menyanthis it is probable that they can reinfect corn. Although they are suspected to be gametes there is no evidence as yet to substantiate this hypothesis. Empty sporangia may renew growth by internal proliferation and produce a sec- 
ond "crop" of zoospores. No evidence of the endobiotic system was found until after the epibiotic phase had produced its spores.

DFPaRTMEN OF Botany,

University of Michigan,

Ans Arbor, Michigan

\section{LITERATURE CITED}

Bïsows, M. 1887. Beitrag zur Kenntniss der Cladochytrien. Cohn. Beitrage Biol. Pflanzen 4:269-283, plate 15.

Cinton, G. P. 190z. Cladochytrium Alismatis. Bot. Gaz. 33: 49-61, plates $2-4$.

Enorss, A. H. 1933. Infection of corn plants by Physoderma zene-maydis Shaw. Jour. Agric. Res, 46: $241-$ 253.

Joxes, F. R., Axo C. Drechsiter. 1920. Crownwart of alfalfa caused by Urophlyctis alfalfae. Jour. Agric. Res, $20: 295-323$, plates $47-56$.

OJfrholm, El.zabetir. 1934. Multiciliate zoospores in
Physoderma zeae-maydis. Bull. Torrey Bot. Club 61 : 13-18.

Silaw, F. J. F. 1912. In H. and P. Sydow, and E. J. Butler. Fungi Indiae orientalis. Ann. Mycologici $10: 243-280,11$ fig.

Spsrrow, F. K. 1934. The occurrence of true sporangia in the Physoderma disease of corn. Science (N.S.) 79 : $563-564$.

- - 1940. Chytridiaceous fungi in relation to disease in flowering plants, with special reference to Physoderma. Abstracts of Communications, Third Inter. Congress for Microbiology, New York. 883 pp. New York.

1946. Observations on Chytridiaceous Parasite of Phanerogams. I. Physoderma Menyanthis de Bary. Amer. Jour. Bot. 33: 112-118, 41 fig.

'Trsidale, W. H. 1919. Physoderma disease of corn. Jour. Agric. Res. 16: 137-154, plates A, B; 10-17.

Vooriers, R. K. 1933 . Effect of certain environmental factors on the germination of the sporangia of Physodermu zene-maydis. Jour. Agric. Res, 47:609615. 